\title{
Which Are the Most Relevant Questions in the Assessment of Outcome after Distal Radial Fractures?
}

\author{
Donald Buchanan, ${ }^{1}$ D. Prothero, ${ }^{2}$ and J. Field ${ }^{3}$ \\ ${ }^{1}$ Department of Trauma \& Orthopaedics, Good Hope Hospital, Rectory Road, Sutton Coldfield B75 7RR, UK \\ ${ }^{2}$ Medical Statistician, Avon IMßT Consortium, NHS Bristol, South Plaza, Marlborough Street, Bristol BS1 3NX, UK \\ ${ }^{3}$ Department of Trauma \& Orthopaedics, Cheltenham General Hospital, Sandford Road, Cheltenham GL53 7AN, UK \\ Correspondence should be addressed to Donald Buchanan; ddarwinb@gmail.com
}

Received 27 July 2015; Accepted 7 December 2015

Academic Editor: Robert F. Ostrum

Copyright (C) 2015 Donald Buchanan et al. This is an open access article distributed under the Creative Commons Attribution License, which permits unrestricted use, distribution, and reproduction in any medium, provided the original work is properly cited.

\begin{abstract}
A study was designed to determine which wrist scoring system best correlates with patient satisfaction and which individual variables predict a satisfactory outcome. We looked at forty-five females and 5 males with wrist fractures at 12 weeks after injury and compared their level of satisfaction with various respected outcome measures. The mean age was 66 years. Multivariate regression analysis was carried out using a statistical software package. Patient satisfaction correlated best with the MacDermid, Watts, and DASH scores. The variables in these scoring systems that predicted satisfaction were pain and ability to perform household chores or usual occupation, open packets, and cut meat. The four most important questions to ask in the clinic following wrist fractures are about severity of pain and ability to open packets, cut meat, and perform household chores or usual occupation. This may provide simple and more concise means of assessing outcome after distal radial fractures. Level of evidence is level 4.
\end{abstract}

\section{Introduction}

Outcome assessment is important in evaluating the efficacy of different treatment strategies and improving patient care. Health care providers use outcome assessment to assess the quality and value of care. Some of the more useful scoring systems for the assessment of outcome following fractures of the distal radius are set out below.

(i) Gartland Jr. and Werley [1] introduced a demerit score which combines the subjective evaluation of pain, limitation of motion, and disability with the objective evaluation of deformity, range of motion, presence of complications, and radiographic changes of arthritis. Scores range from $0-2$ (excellent) to more than 21 (poor). This score was widely used despite its lack of validation studies.

(ii) Sarmiento et al. [2] modified the Gartland and Werley score by adding grip strength to the objective evaluation; a grip strength of $60 \%$ or less of the opposite side scored 1 point. (iii) The Mayo Wrist score [3] has two subjective parameters, pain and functional status, each of which is awarded 25 points. Each objective parameter, range of motion, and grip strength is awarded 25 points. An excellent score is 90 to 100 and a poor score is less than 65. Neither the Sarmiento nor the Cooney score has been validated.

The above scores rely on formal clinical assessment as well as radiological parameters [1]. An outpatient visit is required and is thus costly and time consuming. What is measured by traditional functional metrics does not always translate to outcome desired by the patient, healthcare provider, or society. This has emphasised the need to use patient reported outcome metrics in the assessment of upper extremity disease.

(i) The Patient-Rated Wrist Evaluation [4] provides a brief, reliable, and valid measure of patient-rated pain and disability; the score ranges from 0 (no pain or disability) to 100 .

(ii) The Disability of Arm, Shoulder, and Hand (DASH) Score [5] is a self-administered, region specific quality 
of life instrument which contains thirty questions, twenty-one of which relate to upper extremity functional activities and two of which relate to upper extremity pain. The score ranges from 0 (no disability) to 100 (severe disability). DASH has good validity, reliability, and responsiveness $[6,7]$. Patients take 10 to 15 minutes to complete the questionnaire and the administrator requires 10 minutes to compute the score making it a time consuming outcome instrument. Beaton et al. [8] produced the Quick DASH an abbreviated version of the DASH score which has eleven questions. This has been validated by several authors including Gummesson et al. [9] and Matheson et al. [10].

(iii) The hand function score [11] is a subjective hand function scoring system based on twenty-five commonly performed activities of daily living. The range of the total score is from 25 to 100 (the worst score). The authors showed a positive correlation between the hand function score on admission and both severity of injury and length of time off work but the score has not been validated.

In a busy fracture clinic it would be helpful to have a quick way of assessing outcome after distal radial fractures; it would be helpful to define a few questions that could be used to rapidly assess these patients. A study was designed to determine which variables predict patient satisfaction with the outcome after distal radial fractures.

\section{Material and Methods}

Over the period of 1 year, fifty adult patients who had sustained a distal radius fracture were evaluated during followup in a district general hospital fracture clinic. Intra-articular, extra-articular, and closed as well as open distal radius fractures were included. Informed consent was obtained before inclusion in the study. Patients below the age of 18 years and those not agreeing to participate were excluded. There were forty-five women and 5 men (Table 1) with an average age of 66 years (range of 18-93 years). Most of the fractures were classified as Frykman I to Frykman III (Table 2). Fractures were fixed either with $\mathrm{K}$ wires or a plate through a volar approach. All patients, including those in whom the fracture was fixed, were immobilised in a below elbow plaster of Paris cast for six weeks and reviewed six weeks after removal of the plaster. None of the patients were treated with an external fixator.

All participants completed a comprehensive questionnaire which incorporated all the questions included in the six scoring systems considered in this study. The patients recorded their satisfaction with the outcome of treatment on a 10-centimeter-long visual analogue scale [12] which ranged from not at all satisfied (0) to completely satisfied (10). Clinical examination focused on the parameters defined in the above scoring systems. Grip strength was measured using a Jamar dynamometer [13].
TABLE 1: Demographics of study group $(n=50)$.

\begin{tabular}{lcc}
\hline & & Number of patients \\
\hline \multirow{2}{*}{ Sex } & Males & 5 \\
& Females & 45 \\
\hline \multirow{2}{*}{ Handedness } & Right & 49 \\
& Left & 1 \\
\hline \multirow{2}{*}{ Side affected } & Right & 16 \\
& Left & 34 \\
\hline
\end{tabular}

TABLE 2: Fracture pattern on initial postinjury X-rays.

\begin{tabular}{lc}
\hline Frykman classification & Number of patients \\
\hline I & 13 \\
II & 10 \\
III & 17 \\
IV & 1 \\
V & 3 \\
VI & 2 \\
VII & 3 \\
VIII & 1 \\
\hline
\end{tabular}

2.1. Statistical Methods. The relationship between the patient satisfaction score and the total score from each of the six scoring systems was initially examined by computing the Pearson correlation coefficient. A multiple regression analysis was then undertaken to examine the relationship between the score for each system (including patient satisfaction) and the overall scores for the other 6 systems. The relationship between the overall scores for each system was also examined in relation to the individual components included in each of the six systems. In each case, the regression model was chosen such that the "fit" was not significantly improved through inclusion of additional variables but for which the "fit" was significantly worse if any of the variables included were removed.

The stepwise multiple regression analysis of the overall score for each system on the individual components within that system was used to identify the key variables within each individual system. The proportion of the total variation explained by each component was determined in decreasing order of magnitude. The key variables in each system were defined as those which explained the highest proportion of the total variation and which together accounted for at least 95\% of the total variation.

An overall set of key variables was then created based on all of the variables which featured in at least one of the individual scoring systems. Stepwise multiple regression analysis was then undertaken for each scoring system using the overall set of key variables as independent variables in order to identify a small subset of variables which contributed most in explaining the overall variation within the scoring systems.

2.2. Sample Size Calculation. The computation of sample size was arrived at on the basis of the correlation between patient satisfaction and the total scores generated by each system. 
TABLE 3: Correlation matrix using Pearson correlation of patient satisfaction with six scoring systems (based on 50 observations).

\begin{tabular}{|c|c|c|c|c|c|c|c|}
\hline Scoring system & $\begin{array}{c}\text { Patient } \\
\text { satisfaction }\end{array}$ & MacDermid & DASH & $\begin{array}{l}\text { Gartland and } \\
\text { Werley }\end{array}$ & Sarmiento & Cooney & Watts \\
\hline $\begin{array}{l}\text { Patient } \\
\text { satisfaction }\end{array}$ & 1 & $\begin{array}{c}-.394 \\
\left(0.005^{* *}\right)\end{array}$ & $\begin{array}{c}-.284 \\
\left(0.046^{*}\right)\end{array}$ & $\begin{array}{l}-0.249 \\
(0.081)\end{array}$ & $\begin{array}{c}-0.26 \\
(0.068)\end{array}$ & $\begin{array}{c}0.215 \\
(0.133)\end{array}$ & $\begin{array}{c}-.364 \\
\left(0.009^{* *}\right)\end{array}$ \\
\hline MacDermid & $\begin{array}{c}-.394 \\
\left(0.005^{* *}\right)\end{array}$ & 1 & $\begin{array}{c}.949 \\
\left(0^{* *}\right)\end{array}$ & $\begin{array}{c}.702 \\
\left(0^{* *}\right)\end{array}$ & $\begin{array}{c}.710 \\
\left(0^{* *}\right)\end{array}$ & $\begin{array}{c}-.368 \\
\left(0.009^{* *}\right)\end{array}$ & $\begin{array}{c}.935 \\
\left(0^{* *}\right)\end{array}$ \\
\hline DASH & $\begin{array}{c}-.284 \\
\left(0.046^{*}\right)\end{array}$ & $\begin{array}{c}.949 \\
\left(0^{* *}\right)\end{array}$ & 1 & $\begin{array}{c}.737 \\
\left(0^{* *}\right)\end{array}$ & $\begin{array}{c}.738 \\
\left(0^{* *}\right)\end{array}$ & $\begin{array}{c}-.397 \\
\left(0.004^{* *}\right)\end{array}$ & $\begin{array}{l}.903 \\
\left(0^{* *}\right)\end{array}$ \\
\hline $\begin{array}{l}\text { Gartland and } \\
\text { Werley }\end{array}$ & $\begin{array}{l}-0.249 \\
(0.081)\end{array}$ & $\begin{array}{c}.702 \\
\left(0^{* *}\right)\end{array}$ & $\begin{array}{c}.737 \\
\left(0^{* *}\right)\end{array}$ & 1 & $\begin{array}{l}.997 \\
\left(0^{* *}\right)\end{array}$ & $\begin{array}{l}-.565 \\
\left(0^{* *}\right)\end{array}$ & $\begin{array}{c}.787 \\
\left(0^{* *}\right)\end{array}$ \\
\hline Sarmiento & $\begin{array}{c}-0.26 \\
(0.068)\end{array}$ & $\begin{array}{c}.710 \\
\left(0^{* *}\right)\end{array}$ & $\begin{array}{c}.738 \\
\left(0^{* *}\right)\end{array}$ & $\begin{array}{l}.997 \\
\left(0^{* *}\right)\end{array}$ & 1 & $\begin{array}{l}-.579 \\
\left(0^{* *}\right)\end{array}$ & $.798\left(0^{* *}\right)$ \\
\hline Cooney & $\begin{array}{c}0.215 \\
(0.133)\end{array}$ & $\begin{array}{c}-.368 \\
\left(0.009^{* *}\right)\end{array}$ & $\begin{array}{c}-.397 \\
\left(0.004^{* *}\right)\end{array}$ & $\begin{array}{l}-.565 \\
\left(0^{* *}\right)\end{array}$ & $\begin{array}{l}-.579 \\
\left(0^{* *}\right)\end{array}$ & 1 & $\begin{array}{c}-.455 \\
\left(0.001^{* *}\right)\end{array}$ \\
\hline Watts & $\begin{array}{c}-.364 \\
\left(0.009^{* *}\right)\end{array}$ & $\begin{array}{c}.935 \\
\left(0^{* *}\right)\end{array}$ & $\begin{array}{c}.903 \\
\left(0^{* *}\right)\end{array}$ & $\begin{array}{l}.787 \\
\left(0^{* *}\right)\end{array}$ & $\begin{array}{l}.798 \\
\left(0^{* *}\right)\end{array}$ & $\begin{array}{c}-.455 \\
\left(0.001^{* *}\right)\end{array}$ & 1 \\
\hline
\end{tabular}

Significance levels are in parentheses. The asterisks indicate statistically significant results.

When the true correlation coefficient is zero, it can be shown that the statistic $\sqrt{ } r(n-2) /\left(1-r^{2}\right)$ has a $t$ distribution with $n-2$ degrees of freedom where $r$ is the observed correlation coefficient and $n$ is the number of observations within the sample. The correlation is significantly different from zero at the five percent significance level if the above statistic is greater than or equal to $t_{.05} n-2$. It can be shown that for an observed correlation coefficient of 0.35 to be significantly different from zero at a $5 \%$ level of significance and with a power of $80 \%$ then a sample size of 49 is required.

\section{Results}

The mean satisfaction score was 7.9. Eleven of the patients were completely satisfied with the outcome of the treatment. There was poor correlation between the patient satisfaction score and the Frykman classification of the fracture pattern (Figure 1). Spearman's rho coefficient for the relationship between patient satisfaction and Frykman score was 0.09 (not significant).

When the correlation (Table 3) between each pair of scoring systems (based on the overall score associated with each of the 6 systems) and the patient satisfaction score was examined there was a highly significant correlation $(p<$ 0.01 ) between the scores for the 6 systems. There was also a highly significant correlation between patient satisfaction and the MacDermid $(-0.39)$ and Watts $(-0.36)$ systems. The correlation between the patient satisfaction and the DASH system $(-0.28)$ was only moderately significant $(p<$ $0.05)$. No significant correlation $(p>0.05)$ was shown between patients' satisfaction and the Gartland and Werley and Sarmiento and Cooney systems.

The summary of the results of undertaking a multiple regression analysis of the overall score for each individual system on the overall scores for all other systems (Table 4) explains the extent to which the scoring systems (and patient

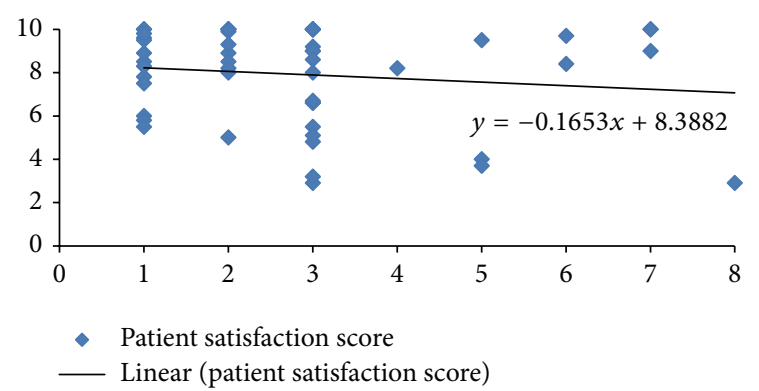

FIGURE 1: Plot of patient satisfaction score ( $y$-axis) versus Frykman class ( $x$-axis).

satisfaction) contribute to the other scoring systems and may indicate the degree of overlap. In each case the table highlights the "best" combination of explanatory variables; that is, the inclusion of any additional variables will not significantly improve the fit of the model.

The MacDermid and DASH scoring systems are the only systems that feature as explanatory variables for the patient satisfaction score, although together they account for only twenty percent of the total variation. Patient satisfaction featured as an explanatory variable for only 2 of the scoring systems, that is, the MacDermid and DASH scores. The MacDermid, Gartland, and Werley and patient satisfaction all made significant independent contributions in explaining the DASH score, whereas the questions in the Sarmiento, Cooney, and Watts systems contributed nothing further.

From the analysis based on the component variables highlighted (Table 5), four variables, namely, ability to perform usual occupation (including housework), ability to open packets, ability to cut meat, and severity of pain, account for $94 \%$ of the variation associated with the MacDermid score, $91 \%$ of the Watts score, and $93 \%$ of the DASH score. However, these 4 variables account for only $56 \%$ of the Gartland and 
TABLE 4: Summary of stepwise regression analysis of each scoring system on all other scoring systems.

Summary of stepwise regression analysis of each scoring system on all other scoring systems

\begin{tabular}{|c|c|c|c|c|c|}
\hline $\begin{array}{l}\text { Dependent } \\
\text { variable }\end{array}$ & $\begin{array}{l}\text { Combination of independen } \\
\text { the }\end{array}$ & $\begin{array}{l}\text { es explaining a } \\
n \text { within the de }\end{array}$ & $\begin{array}{l}\text { stically signif } \\
\text { lent variable }\end{array}$ & $t(p<0.05)$ amount of & $\begin{array}{l}\text { Percentage of } \\
\text { variation } \\
\text { explained }\end{array}$ \\
\hline Patient satisfaction & MacDermid & DASH & & & $20.4 \%$ \\
\hline MacDermid & DASH & Watts & $\begin{array}{c}\text { Patient } \\
\text { satisfaction }\end{array}$ & $\begin{array}{c}\text { Gartland and } \\
\text { Werley }\end{array}$ & $94.1 \%$ \\
\hline DASH & MacDermid & $\begin{array}{c}\text { Gartland and } \\
\text { Werley }\end{array}$ & $\begin{array}{c}\text { Patient } \\
\text { satisfaction }\end{array}$ & & $91.3 \%$ \\
\hline $\begin{array}{l}\text { Gartland and } \\
\text { Werley }\end{array}$ & Sarmiento & & & & $99.5 \%$ \\
\hline Sarmiento & Gartland and Werley & Watts & & & $99.5 \%$ \\
\hline Cooney & Sarmiento & & & & $32.2 \%$ \\
\hline Watts & MacDermid & Sarmiento & & & $90.7 \%$ \\
\hline
\end{tabular}

TABLE 5: Percentage of variation within each scoring system explained by subsets of variables ( $n=$ number of variables).

\begin{tabular}{|c|c|c|c|c|c|c|c|c|}
\hline \multicolumn{9}{|c|}{ Scoring system } \\
\hline Variables & $n$ & Gartland and Werley & Sarmiento & Cooney & DASH & Watts & MacDermid & Patient satisfaction \\
\hline $\begin{array}{l}\text { Opening packets, } \\
\text { cutting meat, work } \\
\text { (including } \\
\text { housework), worst } \\
\text { pain }\end{array}$ & 4 & $56 \%$ & $58 \%$ & $26 \%$ & $93 \%$ & $91 \%$ & $94 \%$ & $23 \%$ \\
\hline $\begin{array}{l}\text { Opening packets, } \\
\text { cutting meat, } \\
\text { housework, worst } \\
\text { pain }\end{array}$ & 4 & $56 \%$ & $58 \%$ & $20 \%$ & $90 \%$ & $90 \%$ & $85 \%$ & $22 \%$ \\
\hline $\begin{array}{l}\text { Opening packets, } \\
\text { cutting meat, worst } \\
\text { pain, work }\end{array}$ & 4 & $55 \%$ & $57 \%$ & $24 \%$ & $83 \%$ & $89 \%$ & $93 \%$ & $23 \%$ \\
\hline Work & 1 & $30 \%$ & $31 \%$ & $4 \%$ & $77 \%$ & $64 \%$ & $84 \%$ & $5 \%$ \\
\hline Opening packets & 1 & $47 \%$ & $49 \%$ & $24 \%$ & $57 \%$ & $76 \%$ & $58 \%$ & $1 \%$ \\
\hline Cutting meat & 1 & $45 \%$ & $47 \%$ & $17 \%$ & $60 \%$ & $76 \%$ & $70 \%$ & $7 \%$ \\
\hline Housework & 1 & $30 \%$ & $29 \%$ & $12 \%$ & $74 \%$ & $50 \%$ & $56 \%$ & $2 \%$ \\
\hline Worst pain & 1 & $21 \%$ & $22 \%$ & $0 \%$ & $43 \%$ & $45 \%$ & $59 \%$ & $19 \%$ \\
\hline
\end{tabular}

Werley score, $58 \%$ of the Sarmiento score, and $26 \%$ of the Cooney score. These four variables are the most relevant variables in explaining the overall variation within the six scoring systems.

Furthermore, they explain a high percentage of the variation within the MacDermid, Watts, and DASH systems, that is, the systems which were most highly correlated with patient satisfaction. The two most important variables were pain and ability to cut meat. Work and house work make a similar contribution and may be used interchangeably.

The percentage of the variation in the score (Table 5) explained by each individual variable is substantially lower for the Gartland and Werley and Sarmiento and Cooney systems than for the DASH, Watts, and MacDermid systems. This is not surprising as, with the exception of pain, the variables identified are of a patient assessed functional nature and do not feature within the Gartland and Werley and Sarmiento and Cooney scoring systems.

\section{Discussion}

Patient satisfaction levels were high at three months following the distal radial fracture. A mean value of $80 \%$ satisfaction would agree with Abraham Colles original treatise. Data analysis however did not show any significant correlation between patient satisfaction and the Gartland and Werley and Sarmiento and Cooney scoring systems. Since one of the most commonly used evaluation systems is the Gartland and Werley system this may be of some concern; however, these systems for the most part provide an objective evaluation of outcome based on assessments by health personnel. In addition, because Gartland Jr. and Werley [1] and Sarmiento et al. [2] use demerit scoring systems it is unusual to find a poor result even at ten years [14].

The lack of correlation may be because a satisfactory radiological appearance or clinical examination predicts neither good functional outcome nor patient satisfaction [15]. Both 
Gartland Jr. and Werley [1] and Sarmiento et al. [2] include radiological parameters as part of their scoring systems. More recently Souer et al. [16] showed that following treatment of distal radial fractures there was no significant correlation between pain and radiological parameters such as volar angulation, ulnar variance, articular congruity, and osteoarthritis.

Three of the scores do correlate with patient satisfaction, the MacDermid, Watts, and DASH scores. Of note is the fact that these scoring systems provide a subjective evaluation of function. They provide a better measure of patient satisfaction with the outcome of treatment. The findings in the current study are consistent with those of Souer et al. [16] who showed only moderate correlation between the Gartland and Werley and Cooney and DASH scores. Pain was the main predictor of outcome in these three scores. Souer et al. [16] support the views of MacDermid et al. [17] who argue that comprehensive evaluation of outcome after distal radial fractures requires assessment of objective physical impairment as well as subjective self-rated disability.

There is obviously significant overlap in the questions involved in the 6 assessment methods. The MacDermid score correlates with patient satisfaction as does the DASH score, despite the latter having no question within it concerning satisfaction. The $99.5 \%$ of contribution made to the Gartland and Werley by the Sarmiento score is not surprising as the latter was developed from the former and this demonstrates the effectiveness of the method of stepwise regression analysis. The fact that Gartland and Werley and MacDermid scores in conjunction with patient satisfaction accrue $91.3 \%$ of the DASH and the Sarmiento, Cooney, and Watts scores contribute nothing further shows the significant level of redundancy in the questions; that is, they are asking similar things.

The current study involved a comparison of six wrist scoring systems only two of which, MacDermid and DASH, have been validated. It shows that four variables, namely, ability to perform usual occupation (including housework), ability to open packets, ability to cut meat, and severity of pain, account for the greatest variation in the six scoring systems. In addition they were the most important in the three questionnaires that correlate most with patient satisfaction (MacDermid, Watts, and DASH). In the clinical setting four questions should be asked in assessing outcome after distal radial fractures. They are as follows. Do you have wrist pain? Can you do your work (including housework)? Can you cut meat? Can you open packets? In ranking importance of the questions, the ability to work and the ability to cut meat are the most important factors. We are currently working on the Distal Radius Assessment Criteria (DRAC) using these 4 questions that could be applied in the clinic situation. The object is to validate this using a larger cohort of patients.

This study is a preliminary study that does have its limitations. It used a small cohort of patients in a district general hospital rather than in level 1 trauma centre. As such most of the injuries were low velocity injuries. Nonetheless, this pilot study indicates that there is the potential to develop a scoring system that is simple, short, and easy to use and may be further investigated.

The Patient Evaluation Measure [18], which is used increasingly in the UK, is a self-administered instrument for outcome assessment of hand and wrist patients; it was validated in a study of scaphoid fracture patients [19] and patients who had carpal tunnel decompression [20]. The PEM was not used in this study as it assesses not only the injury or disease process but also the total care experience.

\section{Ethical Approval}

The study was approved by the South West Medical Research Ethics Committee, UK.

\section{Conflict of Interests}

There were no issues of conflict of interests in carrying out this study.

\section{Acknowledgments}

Joe Mays and Matthew Howl are formerly Clinical Research Fellows at Cheltenham General Hospital and Mr. John McKinnon is Consultant Surgeon, Trauma and Orthopaedics Dept., Cheltenham General Hospital. The study was carried out at Cheltenham General Hospital under the supervision of Mr. Jeremy Field, Consultant Hand Surgeon. Approval for the study was granted by the Regional Medical Research Ethics Committee.

\section{References}

[1] J. J. Gartland Jr. and C. W. Werley, "Evaluation of healed Colles' fractures," The Journal of Bone \& Joint Surgery-American Volume, vol. 33, no. 4, pp. 895-907, 1951.

[2] A. Sarmiento, G. W. Pratt, N. C. Berry, and W. F. Sinclair, "Colles' fractures. Functional bracing in supination," Journal of Bone and Joint Surgery, vol. 57, no. 3, pp. 311-317, 1975.

[3] W. P. Cooney, R. Bussey, J. H. Dobyns, and R. L. Linscheid, "Difficult wrist fractures. Perilunate fracture-dislocations of the wrist," Clinical Orthopaedics and Related Research, vol. 214, pp. 136-147, 1987.

[4] J. C. MacDermid, "Development of a scale for patient rating of wrist pain and disability," Journal of Hand Therapy, vol. 9, no. 2, pp. 178-183, 1996.

[5] P. L. Hudak, P. C. Amadio, and C. Bombardier, "Development of an upper extremity outcome measure: the DASH (disabilities of the arm, shoulder and hand) [corrected]. The upper extremity collaborative group," American Journal of Industrial Medicine, vol. 29, no. 6, pp. 602-608, 1996.

[6] D. E. Beaton, J. N. Katz, A. H. Fossel, J. G. Wright, V. Tarasuk, and C. Bombardier, "Measuring the whole or the parts? Validity, reliability, and responsiveness of the disabilities of the arm, shoulder and hand outcome measure in different regions of the upper extremity," Journal of Hand Therapy, vol. 14, no. 2, pp. 128142, 2001.

[7] R. E. Gay, P. C. Amadio, and J. C. Johnson, "Comparative responsiveness of the disabilities of the arm, shoulder, and hand, the Carpal Tunnel Questionnaire, and the SF-36 to clinical change after carpal tunnel release," Journal of Hand Surgery, vol. 28, no. 2, pp. 250-254, 2003.

[8] D. E. Beaton, J. G. Wright, and J. N. Katz, "Development of the QuickDASH: comparison of three item-reduction approaches," 
The Journal of Bone \& Joint Surgery - American Volume, vol. 87, no. 5, pp. 1038-1046, 2005.

[9] C. Gummesson, M. M. Ward, and I. Atroshi, "The shortened disabilities of the arm, shoulder and hand questionnaire (QuickDASH): validity and reliability based on responses within the full-length DASH," BMC Musculoskeletal Disorders, vol. 7, article 44, 2006.

[10] L. N. Matheson, J. M. Melhorn, T. G. Mayer, B. R. Theodore, and R. J. Gatchel, "Reliability of a visual analog version of the QuickDASH," The Journal of Bone \& Joint Surgery-American Volume, vol. 88, no. 8, pp. 1782-1787, 2006.

[11] A. M. I. Watts, M. Greenstock, and R. P. Cole, "Outcome following the rehabilitation of hand trauma patients. The importance of a subjective functional assessment," Journal of Hand Surgery, vol. 23, no. 4, pp. 485-489, 1998.

[12] E. C. Huskisson, "Measurement of pain," The Lancet, vol. 304, no. 7889, pp. 1127-1131, 1974.

[13] C. O. Bechtol, "Grip test: the use of a dynamometer with adjustable handle spacings," The Journal of Bone \& Joint Surgery-American Volume, vol. 36, no. 4, pp. 820-824, 1954.

[14] J. Field, D. Warwick, G. C. Bannister, and A. G. F. Gibson, "Long-term prognosis of displaced Colles' fracture: a 10-year prospective review," Injury, vol. 23, no. 8, pp. 529-532, 1992.

[15] G. I. Bain, J. H. Roth, D. Pugh, and J. C. MacDermid, "Matched hemiresection interposition arthroplasty of the distal radioulnar joint," The Journal of Hand Surgery, vol. 20, no. 6, pp. 944950, 1995 .

[16] J.-S. Souer, S. A. Lozano-Calderon, and D. Ring, "Predictors of wrist function and health status after operative treatment of fractures of the distal radius," The Journal of Hand Surgery, vol. 33, no. 2, pp. 157.el-157.e8, 2008.

[17] J. C. MacDermid, A. Donner, R. S. Richards, and J. H. Roth, "Patient versus injury factors as predictors of pain and disability six months after a distal radius fracture," Journal of Clinical Epidemiology, vol. 55, no. 9, pp. 849-854, 2002.

[18] A. C. Macey, F. D. Burke, K. Abbott et al., "Outcomes of hand surgery," The Journal of Hand Surgery: British \& European Volume, vol. 20, no. 6, pp. 841-855, 1995.

[19] J. J. Dias, B. Bhowal, C. J. Wildin, and J. R. Thompson, "Assessing the outcome of disorders of the hand: is the patient evaluation measure reliable, valid, responsive and without bias?" The Journal of Bone \& Joint Surgery-British Volume, vol. 83, no. 2, pp. 235-240, 2001.

[20] J. L. Hobby, C. Watts, and D. Elliot, "Validity and responsiveness of the patient evaluation measure as an outcome measure for carpal tunnel syndrome," Journal of Hand Surgery, vol. 30, no. 4, pp. 350-354, 2005. 


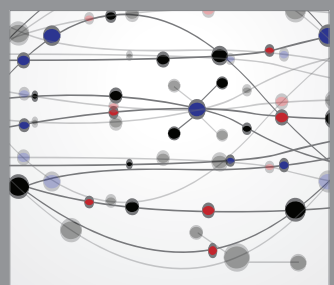

The Scientific World Journal
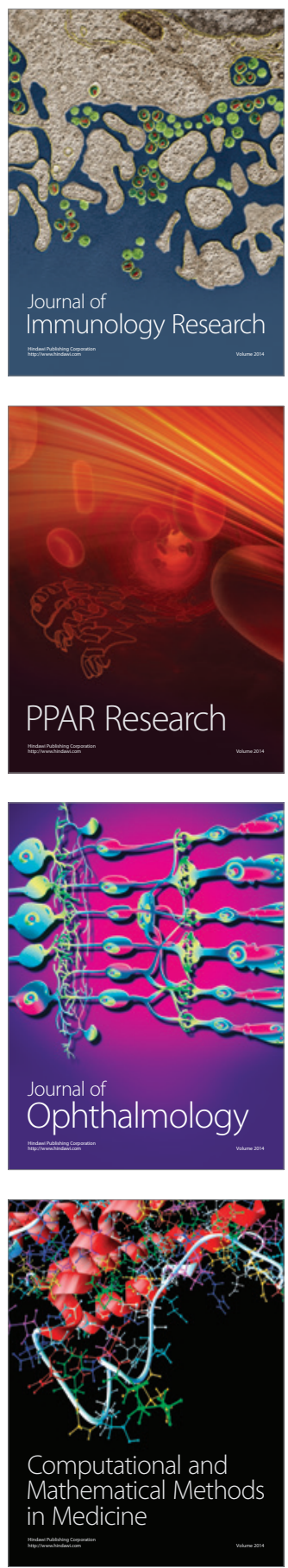

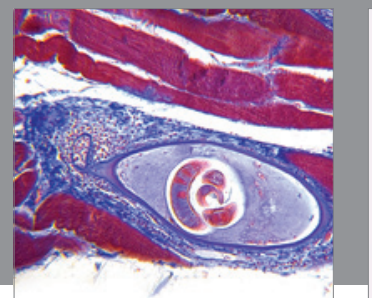

Gastroenterology

Research and Practice
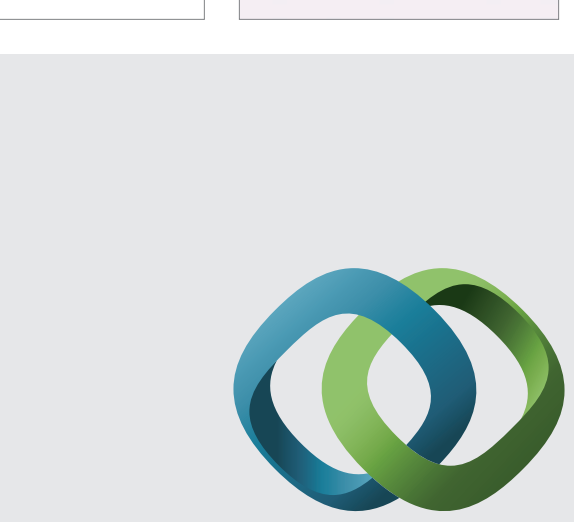

\section{Hindawi}

Submit your manuscripts at

http://www.hindawi.com
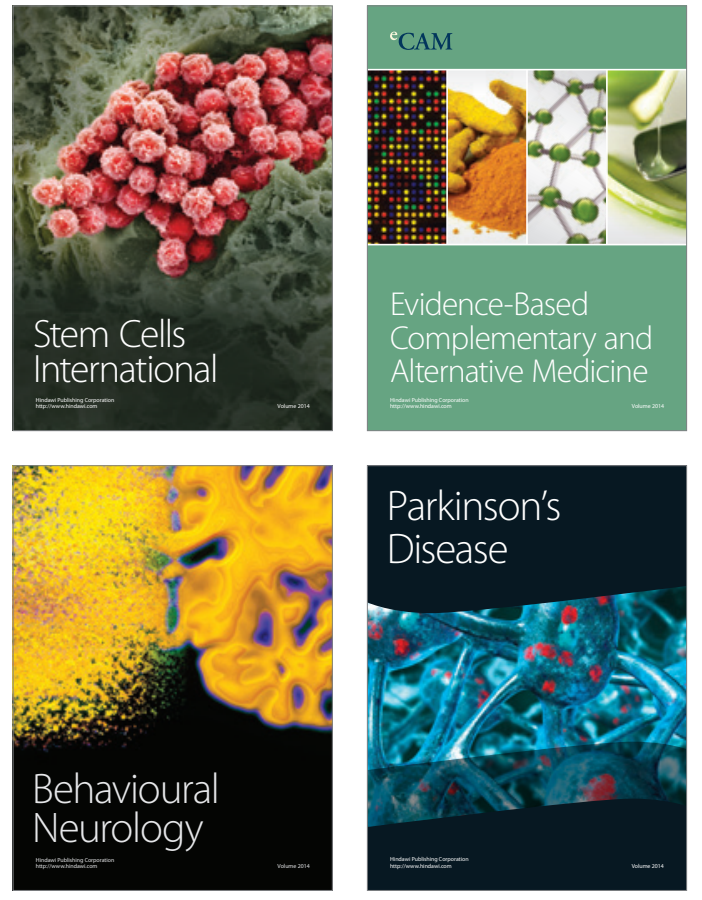
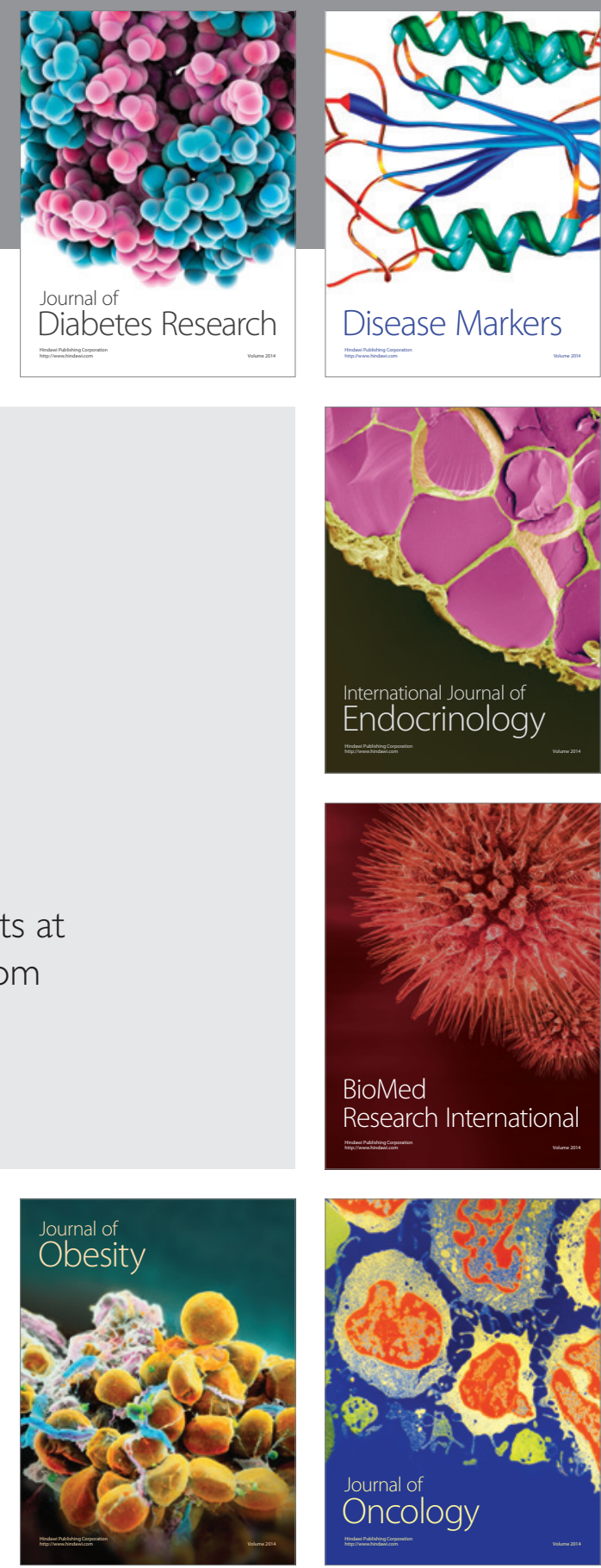

Disease Markers
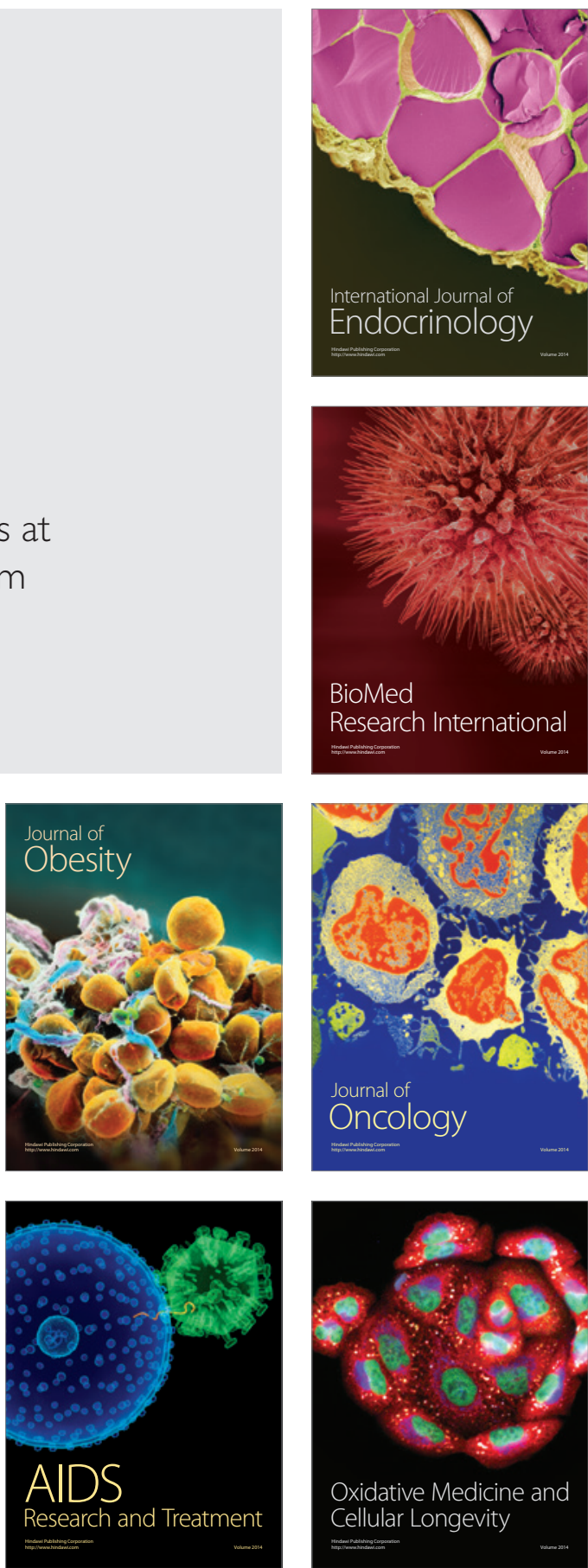